\title{
Recognition memory in Parkinson's disease
}

\author{
KA FLOWERS, ${ }^{*}$ IRIS PEARCE, $\dagger$ JMS PEARCE $\dagger$
}

From the Department of Psychology, University of Hull* and Department of Neurology, Hull Royal Infirmary, $\dagger$ Hull, UK

SUMMARY On four tests of visual recognition memory Parkinsonian patients obtained normal scores, both immediately and after a delay. They also resembled controls closely in nearly all characteristics of memory. Their performance did not correlate with age, motor disability or disease duration: Parkinson's disease does not, therefore, affect this kind of memory.

There have been many reports that Parkinson's disease affects memory. These are, however, inconsistent, ${ }^{1-7}$ as are claims that levodopa treatment improves memory scores. ${ }^{89}$ Often studies using standardised scales such as the Wechsler Memory Scale, or standard tests (for example digit span, recall of stories) have shown either a marginal, or no, deficit in Parkinsonian subjects. ${ }^{2410^{-14}}$ Others have found that drug treatment does not improve memory. 25613 is

In many studies confusion arises because the tests used do not, measure memory impairments directly. Memory scales require not only the acquisition and retention of information, but retrieval of general knowledge, counting backwards and drawing ability also. In other studies where specific learning and memory tasks are used, Parkinsonism may interfere with performance indirectly although the registration and retention of material are intact. ${ }^{1617}$ It may, for example, affect attention, concentration, arousal or motivation ${ }^{31018-20}$ or it may interfere with the patients' ability to execute responses. Where tests are timed or require manipulation of materials, as many do, Parkinsonian patients will be at a disadvantage, and a low level of performance may be attributed in part to impaired motor function.

Whether memory deficits are an intrinsic feature of Parkinsonism is important in relation to current theories that the disease process includes some biochemical or physiological deterioration in the cortex, producing a form of dementia. ${ }^{21-23}$ If this is the case, one should be able to find deficits in memory and understanding in these patients even on

Address for reprint requests: Dr KA Flowers, Department of Psychology, University of Hull, Hull HU6 7RX, UK.

Received 23 June 1983 and in revised form 20 April 1984 Accepted 29 April 1984 tests which minimise or control for their motor symptoms. The study reported here is part of an attempt to clarify the nature of the memory difficulties in Parkinsonism.

In this investigation we were concerned with recognition memory, a task which requires only a minimal motor response and no mental manipulation of material. The intention was to see if the disease affects patients' ability to take in, retain and correctly identify information presented serially for brief periods of time. An impairment of recognition performance has been reported in cases of senile dementia ${ }^{24} 25$ as well as in other kinds of amnesia. ${ }^{26-28}$

Four sequences were used, involving four kinds of visual material, but the procedure was the same in all cases. Subjects were shown a series of items for a few seconds each and asked to look at them carefully. Half the items were then presented for recognition mixed in with new material one minute later (Immediate test), and the other half after a delay of fifteen, thirty or forty-five minutes (Delayed test). An impairment on the Immediate test would indicate that patients had difficulty in registering the information (perhaps due to erratic attention, inability to maintain concentration, or defective shortterm memory), while impairments only on the Delayed test would imply a loss of retention of the information over time, or an impairment in the consolidation of memories within long-term storage. It is deficits of the second kind that are usually found in amnesic states, as for example in those following ECT and head injury, ${ }^{29}{ }^{30}$ the classic amnesic syndrome $^{31}$ or senile dementia. ${ }^{32}$ Patients' scores were correlated with their age, duration of Parkinsonism and current rating of motor disability on the Webster scale.

Of the four tasks used in the investigation, two employed as stimuli material which was easy to ver- 
balise (pictures of common objects and words and numbers) while the other two comprised material which was hard to name or describe (black and white histogram shapes and coloured abstract pictures). We hoped thereby to pick up any marked differences in verbal or non-verbal memory in Parkinsonian subjects. Also, by employing material of varying difficulty in the sequences we hoped to indicate mild to severe amnesic impairments.

On two sequences (Objects and Histograms) we employed a forced-choice procedure. Each old item was presented for recognition together with a set number of new ones, and the subject was required to choose one item as the previously-seen one, guessing if necessary. On the other two sequences a yes-no procedure was adopted. Here subjects were shown a mixture of original and new items, one at a time, and asked to indicate for each one whether or not they thought they had seen it before. With this procedure subjects' scores are affected not only by the power of discrimination available to them, but also by their degree of caution in accepting uncertain items as old, and this level of caution was also compared in patients and controls. Other characteristics of memory examined in the data were the subjects' own rating of certainty in recognition, and serial order effects in degree of recognition for items at each position in the sequence.

\section{Method}

1 Subjects Parkinsonian subjects were from the neurological wards and outpatient clinics of Hull Royal Infirmary. Of 75 patients diagnosed as suffering from the disease 10 had other disabling illnesses or handicaps as well, eight could not be tested for practical reasons and three refused to co-operate. The remaining 54 patients performed on one or more of the recognition tests, there being a different permutation for each sequence. The numbers involved in the four tests are shown in table 1 together with the age range and average age of subjects in each test. Every patient was rated at 6-monthly intervals by an independent observer (IP) on the Webster scale of symptom severity and clinical disability. ${ }^{33}$ Scores on this 30-point scale ranged from 3 to 24 , and recognition scores were correlated with the most recent Webster rating at the time of testing. The correlation of Webster ratings with age just reached significance (at the level $p<0.05$ ) older patients tending to be more severely affected. Patients were also ranked in terms of duration of the disease, estimated from the date reported in the history when they noticed their first symptom. Duration ranged from under a year to 33 years; this did not correlate with the patients' ages.

Four patients had a history mentioning a previous viral infection, suggesting the possibility of a post-encephalitic condition, but none of these was confirmed. All other patients were classified as suffering from idiopathic Parkinsonism. One male patient had had a right-sided stereotaxic operation ten years previously, and one female patient had had operations eleven and fifteen years ago, on the left and right thalamus respectively.

Patients received one or more of the following groups of drugs: anticholinergics (17 patients), levodopa plus a dopa-decarboxylase inhibitor (Sinemet, Madopar: 33 patients) amantadine (11 patients) and bromocriptine (four patients). The drug regime was stable at the time of testing. Occasional patients were taking beta-blockers, antihistamines or tricyclic antidepressants, either for indications unrelated to Parkinson's disease, or as weak adjuvants for Parkinsonian symptoms. Although anticholinergics may theoretically impair memory, its effect in these subjects was obviously negligible since the patients showed no substantial impairment in this experiment (see below).

The Control group was drawn from a pool of 24 patients' spouses, 22 patients with peripheral nerve or spinal cord

Table 1 Test sequences of recognition memory test

\begin{tabular}{|c|c|c|c|c|c|c|c|c|c|c|c|c|}
\hline \multirow[t]{2}{*}{ Test } & & \multicolumn{3}{|c|}{ Subjects } & \multicolumn{2}{|l|}{ Ages } & \multirow{2}{*}{$\begin{array}{l}\text { No of } \\
\text { items in } \\
\text { test }\end{array}$} & \multirow{2}{*}{$\begin{array}{l}\text { Present- } \\
\text { ation } \\
\text { time per } \\
\text { item (s) }\end{array}$} & \multirow{2}{*}{$\begin{array}{l}\text { Immediate } \\
\text { test delay } \\
\text { time (min) }\end{array}$} & \multirow{2}{*}{$\begin{array}{l}\text { Subject's } \\
\text { response }\end{array}$} & \multirow{2}{*}{$\begin{array}{l}\text { Delayed } \\
\text { test delay } \\
\text { time } \\
(\text { min })\end{array}$} & \multirow{2}{*}{ Scoring } \\
\hline & & Men & Women & Total & $\begin{array}{l}\text { Range } \\
(y r)\end{array}$ & $\begin{array}{l}\text { Mean } \\
(y r)\end{array}$ & & & & & & \\
\hline \multirow[t]{2}{*}{ Objects } & Controls & 27 & 21 & 48 & $37-78$ & $62 \cdot 3$ & \multirow[t]{2}{*}{32} & \multirow[t]{2}{*}{5} & \multirow[t]{2}{*}{1} & \multirow{4}{*}{$\begin{array}{l}\text { Forced-choice } \\
(1 \text { of } 5) \\
\text { Choices rated as } \\
\text { Def/Prob/Guess } \\
\text { Forced-choice } \\
(1 \text { of } 2) \\
\text { Choices rated as } \\
\text { Def/Prob/Guess }\end{array}$} & \multirow{2}{*}{45} & \multirow{4}{*}{$\begin{array}{l}\text { Number correct } \\
\text { out of } 16 \\
\text { Number correct } \\
\text { rated as Def. } \\
\text { Number correct } \\
\text { out of } 8 \\
\text { Number correct } \\
\text { rated as Def. }\end{array}$} \\
\hline & Parkinsonians & 30 & 20 & 50 & $39-83$ & $63 \cdot 7$ & & & & & & \\
\hline \multirow[t]{2}{*}{ Histograms } & Controls & 26 & 19 & 45 & $37-78$ & $60-8$ & \multirow[t]{2}{*}{16} & \multirow[t]{2}{*}{10} & \multirow[t]{2}{*}{1} & & \multirow{2}{*}{15} & \\
\hline & Parkinsonians & 28 & 15 & 43 & $39-78$ & $62 \cdot 6$ & & & & & & \\
\hline \multirow[t]{2}{*}{$\begin{array}{l}\text { Words \& } \\
\text { Numbers }\end{array}$} & Controls & 25 & 25 & 50 & $37-78$ & 59.5 & \multirow[t]{2}{*}{24} & 3 & \multirow[t]{2}{*}{1} & $\begin{array}{l}\text { Yes/No for each } \\
\text { item }\end{array}$ & \multirow[t]{2}{*}{45} & \multirow{4}{*}{$\begin{array}{l}\text { Discriminatiol } \\
\text { accuracy }\left(d^{\prime}\right) \\
\text { Criterion }(\beta) \\
\text { Discrimination } \\
\text { accuracy }\left(d^{\prime}\right) \\
\text { Criterion }(\beta) \\
\text { Number of } \\
\text { TNs, FPs, TPs, } \\
\text { FNs rated as } \\
\text { Def }\end{array}$} \\
\hline & Parkinsonians & 30 & 19 & 49 & $\begin{array}{l}37-78 \\
27-78\end{array}$ & $62 \cdot 7$ & & \multirow{3}{*}{10} & & \multirow{3}{*}{$\begin{array}{l}\text { Yes/No for each } \\
\text { item } \\
\text { Choices rated as } \\
\text { Def/Prob/Guess }\end{array}$} & & \\
\hline \multirow{2}{*}{ Abstracts } & Controls & 19 & 16 & 35 & $37-78$ & 61.9 & \multirow{2}{*}{20} & & \multirow[t]{2}{*}{1} & & \multirow{2}{*}{30} & \\
\hline & Parkinsonians & 23 & 11 & 34 & $39-76$ & $61 \cdot 1$ & & & & & & \\
\hline
\end{tabular}


afflictions and 23 local volunteers. The permutation of controls for each sequence was equated as nearly as possible to that of the Parkinsonian group with regard to age, occupation and background. The numbers involved in each sequence and their ages are given in table 1 . None of the Controls had a history of nervous disease or serious head injury, and none was taking drugs which affect the central nervous system.

2 Test Sequences Four test sequences were constructed using four kinds of visual material. Objects consisted of 32 line drawings of common objects presented for 5 seconds each. Their recognition was tested by presenting each item together with four other drawings, which were mostly of similar objects, but in six cases were different views of the same object. Subjects were asked to indicate (by pointing or reading a number under the relevant item) which of the five test items they had seen before, and to say whether their choice was "definite", "probable", or "just a guess". The delayed test was administered 45 minutes after the initial presentation. Histograms comprised 16 histogram shapes each formed from a row of eight black columns on a white background. The height of each column was determined by reference to a random numbers table so as to give an irregular silhouette shape-often called "steps" or "factory chimneys" by subjects. They were presented for inspection for 10 seconds each, and their recognition tested by presenting each item with one other. Subjects had to say whether their choice was definite, probable or a guess. The delayed test was given 15 minutes after the initial presentation. Words and Numbers included a mixed set of six combinations of letters (as LVPA, KLMN), six numbers (as $5209,8,999$ ) and 12 short phrases (as Fish and Chips, Welcome Home, Rasputin Lives!) printed in block characters $10 \mathrm{~mm}$ high on white cards. Items were presented for 3 seconds each, and subjects asked to read out each item as it appeared. In the recognition test old items were presented mixed with an equal number of similar new ones, and subjects had to indicate for each item whether they thought it had appeared before or not (Yes/No test). The delayed test was given 45 minutes after initial presentation. Abstracts comprised 20 coloured modern art pictures by artists such as Mondrian, Klee, Rothko and Pollock. They were trimmed where necessary to remove specific identifying details; no subject admitted ever seeing them before. Each item was presented for 10 seconds. Recognition was tested as in Words-and-Numbers with a yes-no procedure for each item. Subjects also rated their decisions as definite, probable or a guess. The delayed test was given 30 minutes after the end of presentation.

For Words-and-Numbers and Abstracts two versions of the sequence were prepared. The presentation stimuli for the first set were used as the new material for the second set, and vice-versa. Half the subjects in each group, assigned at random, were tested on each version.

Details of the four test sequences appear in table 1. 3 Procedure Most subjects who performed on more than one sequence tackled each test on different days, but some were given two on the same day where time was short, for example, in-patients who would not be available later. Sequences were administered in no special order, largely for practical reasons, resulting in a pseudo-random pattern of presentation. All items were presented on white cards turned over by hand, with their exposure timed with a stopwatch. Subjects were told to look carefully at each item so that they would be able to recognise it when shown again later. The various sequences lasted between $1 \frac{1 / 4}{4}$ and $3 \frac{1}{4}$ minutes of continuous presentation. The Immediate test was given one minute after the end of presentation in all cases, and involved the even-numbered items; oddnumbered items were presented on the Delayed test. The time between Immediate and Delayed tests was filled with tests of motor function or clinical interviews. On Wordsand-Numbers and Abstracts subjects were told before each test that half the items were old and half new.

Scores on the two forced-choice tests (Objects and Histograms) were expressed as number correct out of 16 and 8 respectively; chance scores are then $3 \cdot 2$ and $4 \cdot 0$. Scores on the two yes-no tests were converted to a signal-detectionbased score of accuracy $\left(d^{\prime}\right)$ and criterion level of caution $(\beta)$ calculated on the basis of the proportion of old items correctly identified as old (TPs = true positives or "hit rate") and the proportion of new items incorrectly identified as old (FPs = "false positive rate"). The $d^{\prime}$ accuracy scores are expressed as z-units of the normal distribution. In these sequences a chance score is zero, obtained when the proportion of true positives and of false positives is equal..$^{34} 35$

For the measure of subjective certainty, only the number of correct (TP) "definite" responses were considered, as the number of items falling into each of the other categories was usually small, and some subjects were reluctant to subdivide their ratings other than into "definite" and "non-definite".

Criterion levels $(\beta)$ are expressed as a ratio of the probability of TP responses as against the probability of FP responses.

Comparisons between Control and Parkinsonian groups, and within groups, were made by two-tailed $t$ tests, except for criterion levels, where some outliers in each group were thought to distort the calculations too much. These were therefore compared in terms of median values and tested by the non-parametric Mann-Whitney U-test. Correlations were calculated using the Spearman rank order statistic for all comparisons, as the Webster scale is best regarded as a ranking scale rather than an absolute real-number scale.

\section{Results}

\section{(A) Objects and Histograms}

1 Recognition accuracy The number of items correctly recognised in the two forced-choice sequences are shown in table 2. In both Objects and Histograms Parkinsonian scores matched those of the Controls very closely on both Immediate and Delayed tests and there were no significant differences between them. There was a significant drop in accuracy after a delay on the Objects test, but only a slight drop on Histograms, in both groups. The lack of differences between groups was not due to a ceiling effect on Objects or a floor effect on Histograms because the proportion of each group scoring the 
Recognition memory in Parkinson's disease

Table 2 Accuracy scores: objects and histograms tests

\begin{tabular}{|c|c|c|c|c|c|c|c|}
\hline \multirow[t]{2}{*}{ Objects } & & \multicolumn{3}{|c|}{ Total correct choices } & \multicolumn{3}{|c|}{ "Definite" choices only } \\
\hline & & $\begin{array}{l}\text { Immediate } \\
\text { scores }\end{array}$ & $\begin{array}{l}\text { Delayed } \\
\text { scores }\end{array}$ & $\begin{array}{l}\text { Significance } \\
\text { of drop }\end{array}$ & $\begin{array}{l}\text { Immediate } \\
\text { scores }\end{array}$ & $\begin{array}{l}\text { Delayed } \\
\text { scores }\end{array}$ & $\begin{array}{l}\text { Significance } \\
\text { of drop }\end{array}$ \\
\hline $\begin{array}{l}\text { Controls } \\
(\mathrm{n}=48) \\
\text { Parkinsonians } \\
(\mathrm{n}=50) \\
\text { Difference }\end{array}$ & $\begin{array}{l}X \\
\text { (sd) } \\
\text { X } \\
\text { (sd) }\end{array}$ & $\begin{array}{l}14.96 \\
(1.74) \\
14.68 \\
(1.50) \\
t=0.854 \\
(n s)\end{array}$ & $\begin{array}{l}13.42 \\
(2.37) \\
12.82 \\
(2 \cdot 55) \\
t=1 \cdot 205 \\
(n s)\end{array}$ & $\begin{array}{l}t=5.736 \\
(p<0.001) \\
t=5 \cdot 325 \\
(p<0.001) \\
t=2.129 \\
(p<0.05)\end{array}$ & $\begin{array}{l}14.33 \\
(1.89) \\
13.40 \\
(2.40) \\
t=2.002 \\
(p<0.05)\end{array}$ & $\begin{array}{l}12 \cdot 60 \\
(2 \cdot 82) \\
11 \cdot 40 \\
(3 \cdot 10)\end{array}$ & $\begin{array}{l}t=7.071 \\
(p<0.001) \\
t=5.283 \\
(p<0.001)\end{array}$ \\
\hline $\begin{array}{l}\text { Histograms } \\
\text { Controls } \\
(\mathrm{n}=45) \\
\text { Parkinsonians } \\
(\mathrm{n}=43) \\
\text { Difference }\end{array}$ & $\begin{array}{l}X \\
\text { (sd) } \\
\text { X } \\
\text { (sd) }\end{array}$ & $\begin{array}{l}5 \cdot 04 \\
(1 \cdot 24) \\
4.95 \\
(1 \cdot 25) \\
t=0 \cdot 339 \\
(n s)\end{array}$ & $\begin{array}{l}4.93 \\
(1.19) \\
4.67 \\
(1.27) \\
t=0.991 \\
(n s)\end{array}$ & $\begin{array}{l}t=0.412 \\
(\mathrm{~ns}) \\
\mathrm{t}=1.086 \\
(\mathrm{~ns})\end{array}$ & $\begin{array}{l}3.02 \\
(1.90) \\
2.68 \\
(1.90) \\
t=0.824 \\
\text { (ns) }\end{array}$ & $\begin{array}{l}2.43 \\
(2.00) \\
2.71 \\
(2.08) \\
t=0.632 \\
(n s)\end{array}$ & $\begin{array}{l}t=1.967 \\
(p<0 \cdot 10) \\
t=0.018 \\
(n s)\end{array}$ \\
\hline
\end{tabular}

maximum possible ( $51 \%$ vs $40 \%)$ on the Objects Immediate test or at chance $(24 \%$ vs $33 \%)$ on the Histograms Delayed test was not markedly different in the two groups.

2 Subjective certainty Subjective ratings were combined into two categories, definite and non-definite. The number of correct responses rated as definite is shown for each group on the two sequences in table 2 also. Parkinsonian subjects were significantly less certain of their choices on Objects than were controls, but not markedly so on Histograms. Both groups showed a reduction in certainty after a delay on Objects recognition but only a modest reduction on Histograms. Parkinsonian patients were thus a little less certain of their choices on these sequences, even though their accuracy was normal.

3 Correlation with patient variables Parkinsonian accuracy and certainty scores were correlated with patients' ages, duration of illness and Webster scores. None of these correlations reached significance on either sequence (highest correlation $\left.r_{s}=0 \cdot 284, n s\right)$. There was no correlation of recognition scores with age in Controls either. Dividing subjects by age, the scores for subjects over 60 years old were not worse than those for younger subjects in either group, nor was the difference between Parkinsonians and Controls greater in older subjects. Thus older more deteriorated patients were not more impaired in their recognition capacity than younger, less affected ones. Nor were there any significant differences in subjects on different drug regimens.

4 Order effects in item recognition The number of subjects correctly recognising items at each point in the Objects sequence are shown for both groups in the figure. Control scores were pro-rated by multiplying the numbers by $50 / 48$. The six items which involved different versions of the same object, and which proved less easy to discriminate, are plotted separately. The other items show a similar pattern for both groups. There was a somewhat erratic pattern on the Immediate test, and a distinct serial order effect on the Delayed test, that is items in the middle of the sequence were less well recognised than those at the beginning and the end. Parkinsonian subjects thus showed the same kind of recognition characteristics as Controls, with slightly lower scores all the way through the sequence (not for example only at the beginning or in the middle). The six more difficult items were less well recognised by both groups, but again there was no significant difference between them in the proportion of subjects choosing correctly (on a $\chi^{2}$ test the largest difference was $2 \cdot 18$ for $2 \mathrm{df}$ which was not significant).

The figure shows that although the recognition rate for different items varied a good deal on the Objects sequence, the rate for the Parkinsonian subjects was not abnormally low at any level of accu-

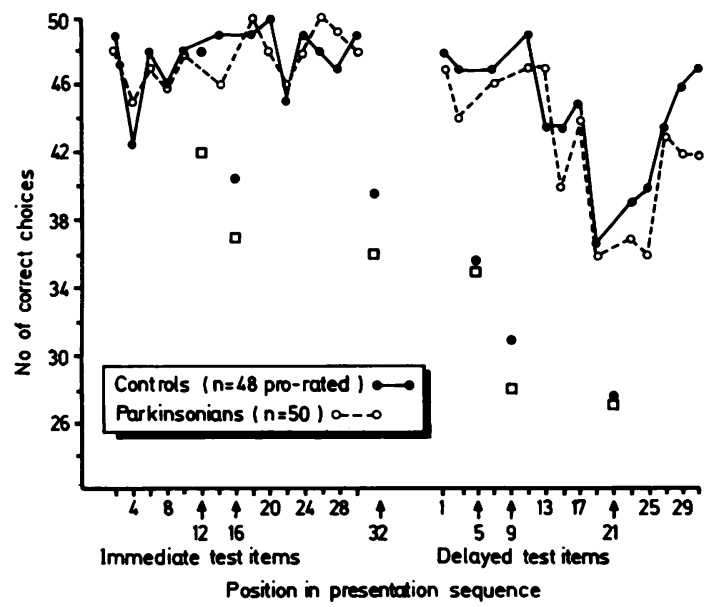

Fig Objects test: order effect in recognition accuracy. 
racy. Nor were their slightly lower scores due to any particular memory failure in the early or late parts of the sequence, (as might occur with specific amnesic impairments or if subjects lost concentration at any point).

There were no order effects of note in the Histograms task.

(B) Words-and-Numbers and Abstracts

Within the Control group there were no differences on any measure between those presented with one set of material initially and those presented with the other, for either of these sequences. In patients just one significant difference was found in each of the Delayed tests (in accuracy), but as each subset of scores showed the same relationship to the equivalent Control subsets, the scores were combined for overall analysis.

1 Recognition accuracy Accuracy of recognition for the two Yes/No sequences is shown in table 3 expressed as $d^{\prime}$ measured in terms of z-units of the normal distribution. Both Control and Parkinsonian groups showed a marked drop in discrimination ability after the delay on the verbal sequence, but only a small drop for pictures. In neither sequence was there any reliable difference between the groups, so Parkinsonian patients recognised both verbal and pictorial material normally even when, like Controls, they showed a drop in accuracy of recognition with time.

2 Criterion point The level of caution adopted by each subject in accepting items as old was measured in terms of $\beta$ estimated also from the proportion of TPs and FPs in each test. Median $\beta$ scores are shown in table 3 also. On Words-and-Numbers criterion levels were the same in Control and Parkinsonian groups for both the Immediate and the Delayed tests. In the Control group the $\beta$ value increased from first to second test in 24 subjects and decreased in 24 , while in two there was no change. In the experimental group 22 subjects increased and 26 subjects decreased their values, there being no change in one. On the Abstracts task $\beta$ increased a little after the delay, implying a slightly greater degree of caution in judgements, but in neither case was the change significant, nor was the comparison between the two groups.

Eleven Control subjects showed decreased values in the Delayed test compared to those shown in the Immediate one, 22 showed an increase and two stayed the same. In the Parkinsonian group 11 showed a decrease, 20 an increase and three no change. Movements in criterion value, therefore, showed no marked trend in either sequence and Parkinsonian patients showed no sign of being more cautious than Controls in making their judgements. 3 Subjective certainty In the Abstracts task subjects said either Yes or No to items that were either old or new, and then rated each choice for certainty. There were thus four categories of up to 10 responses each: True Negative (New-No), False Positive (New-Yes), True Positive (Old-Yes) and False Negative (Old-No), each with separate certainty ratings. Subjective ratings for new items (TNs and FPs) were virtually the same for both groups in both tests. But for old items (TPs and FNs) on the Delayed test the Parkinsonian group had a higher "definite" FN score than Controls $(2 \cdot 4$ cf 3.6: $t=2 \cdot 384, \mathrm{p}<0.05)$ and a lower "definite" TP rating $(4 \cdot 9 \mathrm{cf} 5 \cdot 9: t=$ $2 \cdot 175, \mathrm{p}<0.05)$ implying that they were more certain of their (erroneous) judgements when they missed old items, and less certain when they correctly identified them. As in the Objects sequence, this suggested that Parkinsonian patients, although not showing a reliable drop in accuracy, did appear to find old items slightly less familiar.

4 Correlation with patient variables Correlation of

Table 3 Accuracy $\left(d^{\prime}\right)$ and Criterion $(\beta)$ scores: words-and-numbers and abstracts test

\begin{tabular}{|c|c|c|c|c|c|c|c|}
\hline \multirow{2}{*}{\multicolumn{2}{|c|}{ Words-and-numbers }} & \multicolumn{3}{|l|}{$d^{\prime}$ scores } & \multirow[b]{2}{*}{ test } & \multicolumn{2}{|l|}{$\beta$ scores } \\
\hline & & $\begin{array}{l}\text { Immediate } \\
\text { test }\end{array}$ & $\begin{array}{l}\text { Delayed } \\
\text { test }\end{array}$ & $\begin{array}{l}\text { Significance } \\
\text { of drop }\end{array}$ & & $\begin{array}{l}\text { Immediate } \\
\text { test }\end{array}$ & Delayed \\
\hline $\begin{array}{l}\text { Controls } \\
(n=50) \\
\text { Parkinsonians } \\
(n=49) \\
\text { Difference }\end{array}$ & $\begin{array}{l}\bar{X} \\
(s d) \\
\bar{X} \\
(s d)\end{array}$ & $\begin{array}{l}3.74 \\
(1.49) \\
3.23 \\
(1.60) \\
t=1.637 \\
(n s)\end{array}$ & $\begin{array}{l}2.21 \\
(1.42) \\
1.83 \\
(1.36) \\
t=1.358 \\
(\mathrm{~ns})\end{array}$ & $\begin{array}{l}t=4.631 \\
(p<0.001) \\
t=4.714 \\
(p<0.001)\end{array}$ & $\begin{array}{l}\text { Median } \\
\text { Median }\end{array}$ & $\begin{array}{l}1 \cdot 686 \\
1 \cdot 686 \\
U=1118 \\
z=0.75(\mathrm{~ns})\end{array}$ & $\begin{array}{l}1.545 \\
1.545 \\
U=1184 \\
z=0.29(\mathrm{~ns})\end{array}$ \\
\hline $\begin{array}{l}\text { Abstracts } \\
\text { Controls } \\
(\mathrm{n}=35) \\
\text { Parkinsonians } \\
(\mathrm{n}=34) \\
\text { Difference }\end{array}$ & $\begin{array}{l}\bar{X} \\
(s d) \\
\bar{X} \\
(s d)\end{array}$ & $\begin{array}{l}1.79 \\
(0.93) \\
1.61 \\
(1.26) \\
t=0.676 \\
(n s)\end{array}$ & $\begin{array}{l}1.60 \\
(1.35) \\
1.12 \\
(1.18) \\
t=1.477 \\
(n s)\end{array}$ & $\begin{array}{l}t=1.304 \\
(\mathrm{~ns}) \\
t=1.490 \\
(\mathrm{~ns})\end{array}$ & $\begin{array}{l}\text { Median } \\
\text { Median }\end{array}$ & $\begin{array}{l}0.805 \\
1.000 \\
U=488.5 \\
Z=1.28(\mathrm{~ns})\end{array}$ & $\begin{array}{l}1.033 \\
1.195 \\
U=472 \\
z=1.48(\mathrm{~ns})\end{array}$ \\
\hline
\end{tabular}


Control $d^{\prime}$ and $\beta$ scores with age produced only small negative values in either sequence. Correlation of Parkinsonian $\mathrm{d}^{\prime}$ scores with age, duration and Webster ratings produced small negative values only in all cases on Words-and-Numbers and in all cases but two on Abstracts, where scores on the Immediate test correlated with age and Webster rating (at the level of $p<0.01$ ) in both cases). These results suggested that older subjects may have found the initial test more difficult, but comparison of the scores of subjects over 70 alone, $60-70$ years old alone, and all subjects over 60 , showed no significant differences compared to matched Control scores on either test, so the correlations were unsubstantiated and may have been isolated freak results.

None of the $\beta$ values correlated with age, duration or Webster ratings significantly in either sequence. There were no differences for either accuracy or criterion scores between any Parkinsonian subgroups taking different drugs (especially L-Dopa vs non-Dopa, or anticholinergics vs nonanticholinergics).

5 Order effects in item recognition The discrimination rate for each item in the two sequences was calculated on the basis of the number of subjects correctly or incorrectly recognising each item. The overall level of discriminability varied from item to item, but again the Parkinsonian profile followed the Control one very closely at all points in the sequence.

\section{Discussion}

In all four sequences the most notable finding is how closely Parkinsonian patients resemble Controls in their recognition ability and in the characteristics of their performance. Although their accuracy scores are slightly lower than those of Controls throughout the tests, in no case are the differences large or reliable enough to indicate an impairment in memory associated with Parkinson's disease. They show the same drop in recognition accuracy with a delay as Controls, similar serial order effects, and no difference in criterion levels or in their readiness to register false positives. This latter measure is particularly indicative of a normal performance; Parkinsonian subjects might have been expected, from their general lack of spontaneous behaviour and initiative, to adopt a parsimonious attitude to memory items, only accepting them as repeated if they were well above the normal threshold. That they appear equally willing to "score" FPs indicates that they have not set their criterion lower than normal.

Only on the subjective ratings of certainty for old items is there any indication that memories may be less strong, the feeling of familiarity less compelling, in patients. In two of the three tests where certainty was asked for, the Parkinsonian group show a slightly less definite self-rating for repeat items, although even here the difference is not large.

Otherwise, over a range of measures and material Parkinsonian recognition memory appears quite normal. There is no difference, relative to Controls, between performance on the verbal and non-verbal sequences, and about the same slight difference for material of varying degrees of discriminability. The range of scores of each measure does not differ in the patient groups from that in the control group, and performance on the particularly difficult items (for example the six items on the Objects test which had the lowest accuracy scores, and the Histogram items) does not seem to produce any greater recognition difficulty in patients than do the easier items.

With this in mind it is not surprising that the correlations of Parkinsonian recognition scores with patient variables is low in nearly all cases. As the Webster ratings ranged up to 24 , which is near the limit where testing is clinically possible in these patients, it is clear that even severe Parkinsonism does not affect recognition capacity. This range would include many that might be regarded as demented on clinical grounds, so it seems fair to conclude that, were there any such mental disturbances, they do not affect recognition either (the IQs of our subjects were not rated formally, but all of them scored 90 or more on an abbreviated Wechsler verbal IQ battery). Nor do there appear to be any drug effects on these tests.

These negative findings are perhaps surprising in view of the frequent complaints of bad memory by patients and reports of low scores on memory tests made by investigators. Our largely negative results, however, are in agreement with what little previous data there are on recognition memory in Parkinsonism. Tasks requiring recognition rather than recall have not been used very often before, and of those that have, few have reported their test procedures and results clearly. But what evidence there is supports our contention that Parkinsonian patients are not impaired at recognition. Asso et al $^{36}$ employed a battery of paired associate learning tests devised by Meyer, tests 3 and 4 of which were described as "visual verbal recognition" and "visual designs recognition" (further details not given). Unlike the recall tests in the battery, the recognition tests were briefly reported as showing no differences between patients and controls either before or after the patients' thalamic operations. Perret $e$ a $^{\mathbf{l}^{37}}$ showed two Parkinsonian groups 12 nonsense-figure items on a sheet for 45 seconds, and then asked them to pick out the original items from a sheet of 32 immediately, and again after one hour. There were no control scores to show whether Parkinsonian per- 
formance was abnormal, but the fact there was no difference between subjects undergoing left- or right-sided operations either before or after thalamotomy suggests that it was not. Lees and Smith $^{38}$ reported no deficit on two forced-choice recognition tasks using words and faces as stimuli.

Using an auditory recognition procedure, Garron et $a l^{16}$ and Wilson et $a l^{17}$ asked subjects to say whether a probe digit had appeared in a digit set presented just beforehand. Significantly both these controlled studies reported no differences between Controls and Parkinsonian subjects in accuracy of recognition, although both claimed that patients responded more slowly. Similarly investigations using the Seashore tests (which are in effect auditory recognition tests) have only occasionally found deficits in Parkinsonian subjects. Marsh et $\mathrm{al}^{2}$ found no differences on "tonal memory" (whether two tunes have the same notes) although there was a difference on "tune duration" (which of two tunes is longer) and "rhythm" (whether two tapping sequences are in the same rhythm) at the level $p<0.05$. Reitan and Boll' found an effect on the rhythm test, but Matthews and Haaland ${ }^{20}$ did not. Asso et al $^{36}$ reported a temporary slight impairment in Parkinsonian subjects on an "auditory verbal recognition task" after a thalamic operation, but none before or 9 months afterwards. In the only investigation to measure bodily sensation, Bowen et al $^{5}$ claimed that their results with tests of body tilt and limb position imply that Parkinsonian subjects have a tactilekinaesthetic short-term memory deficit, but no details of the rationale for this conclusion were given.

The evidence to date, then, suggests that whatever is the cause of poor Parkinsonian performance on other memory tests, it is not a typical amnesic deficit. Parkinsonian subjects are registering and retaining information as efficiently as normal subjects of their own age. Their difficulties must begin at the retrieval or some higher level processing stage.

In contrast to recall and learning tests, recognition is a "passive" memory situation. Subjects do not have to manipulate the material, nor mentally "scan" it as in the Sternberg STM probe test. ${ }^{17}$ Nor do they have to organise actively a response as with recall and paired associate learning tests. A simple decision between fixed alternatives is all that is required. Such tests can be regarded as maximising Parkinsonian subjects' ability by tapping only those mental operations of perception and passive information retention (that is, posterior cortical functions) that are still intact in these patients. Other memory activities such as recall and learning, which require more active participation of the subject to perform adequately may be more difficult for them. ${ }^{26}$

Such a difference may explain why Parkinsonian patients give such ambiguous impressions as to their mental state. Sometimes they seem to be behaviourally very abnormal and to be mentally impaired, at others they surprise one by showing unexpected knowledge, memory or understanding. Perhaps they are registering events and information well enough, but whether they can demonstrate it depends on the means of expression they try (or are allowed) to use. When the response required of them is compatible they may appear quite normal. Whatever their mental deficits, a pure amnesic loss of information registration and storage does not appear to be one of them.

This work was supported by grants from the Yorkshire Regional Health Authority and the Parkinson's Disease Society of Great Britain. We are indebted to Hull Branch of PDS for volunteering subjects, Dr Sheila Zinkin for some stimulus material, Colin Robertson for help with testing subjects, Mr G Whitehead of Hull Royal Infirmary Medical Illustration Department for photographic work, and Mrs Marion Day and Miss Frances Hunt for secretarial assistance.

\section{References}

${ }^{1}$ Reitan RM, Boll TJ. Intellectual and cognitive function in Parkinson's disease. J Consult Clin Psychol 1971;37:364-9.

${ }^{2}$ Marsh GG, Markham CM, Ansel R. Levodopa's awakening effect on patients with Parkinsonism. $J$ Neurol Neurosurg Psychiatry 1971;34:209-18.

${ }^{3}$ Horn S. Some psychological factors in Parkinsonism. $J$ Neurol Neurosurg Psychiatry 1974;37:27-31.

${ }^{4}$ Elithorn A, Lunzer M, Weinman J. Cognitive deficits associated with chronic hepatic encephalopathy and their response to levodopa. J Neurol Neurosurg Psychiatry 1975;38:794-8.

${ }^{5}$ Bowen FP, Brady EM, Yahr MD. Short and Long Range studies of Memory Intelligence and Perception in Parkinsonian patients treated with Levodopa. In: Siegfried J, ed. Parkinson's Disease: Rigidity, Akinesia and Behavior. Vol 2. Bern: Hans Huber Publishers, 1973;315-24.

- Halgin R, Riklan M, Misiak H. Levodopa, Parkinsonism and Recent Memory. J Nerv Ment Dis 1977; 164:268-72.

${ }^{7}$ Mortimer JA, Pirozzolo FJ, Hansch EC, Webster DD. Relationship of motor symptoms to intellectual deficits in Parkinson's disease. Neurology $(\mathrm{Ny})$. 1982;32:133-7.

${ }^{8}$ Beardsley JV, Puletti F. Personality (MMPI) and Cognitive (WAIS) changes after levodopa treatment. Arch Neurol 1971;25:145-50. 
${ }^{9}$ Loranger AW, Goodell H, Lee JE, McDowell F. L-Dopa treatment of Parkinson's syndrome: improved intellectual functioning. Archs gen Psychiatry 1972;26:163-168.

${ }^{10}$ Talland GA. Cognitive functions in Parkinson's disease. J Nerv Ment Dis 1962;135:196-205.

1 McFie J. Psychological effects of stereotaxic operations for the relief of Parkinsonian symptoms. J Ment Sci 1960;106:1512-7.

12 Asso D. WAIS Scores in a group of Parkinson patients. Br J Psychiatry 1969; 115:555-6.

${ }^{13}$ Arbit J, Boshes B, Blonsky R. Behavior and mentation changes during therapy. In: Barbeau A, McDowell FH, eds. L-Dopa and Parkinsonism. Philadelphia: FA Davis.

${ }^{14}$ Meier MJ, Martin WE. Intellectual changes associated with Levodopa therapy. JAMA 1970;213:465-6.

${ }^{15}$ Donnelly EF, Chase TN. Intellectual and memory function in Parkinsonian and non-Parkinsonian patients treated with L-Dopa. Dis Nerv Sys 1973;34:119-23.

${ }^{16}$ Garron DC, Klawans HL, Narin F. Intellectual functioning of persons with idiopathic Parkinsonism. J Nerv Ment Dis 1972;154:445-52.

17 Wilson RS, Kaszniak AW, Klawans HL, Garron DC. High speed memory scanning in Parkinsonism. Cortex 1980;16:67-72.

${ }^{18}$ Aubrun W. Reponses aux emotions chez les Parkinsoniens. Annee Psychol 1937;37:140-71.

${ }^{19}$ Horvath TB, Meares RA. L-Dopa and Arousal. J Neurol Neurosurg Psychiatry 1974;37:416-21.

${ }^{20}$ Matthews CG, Haaland KY. The effects of symptom duration on cognitive and motor performance in Parkinsonism. Neurology (Minneap) 1979;29:951-6.

${ }^{21}$ Pearce JMS. Mental changes in Parkinsonism. Br Med J 1974;(i):449.

${ }^{22}$ Drachman DA, Stahl S. Extrapyramidal dementia and levodopa. Lancet 1975;(i):809.

${ }^{23}$ Pirozzolo FJ, Hansch EC, Mortimer JA, Webster DD,
Kuskowski MA. Dementia in Parkinson disease: a neuropsychological analysis. Brain and Cognition 1982; 1:71-83.

${ }^{24}$ Whitehead A. Recognition memory in dementia. Br J Soc Clin Psychol 1975;14:191-4.

${ }^{25}$ Williams $\mathrm{M}$, Owen $\mathrm{C}$. Word versus picture recognition in amnesic and aphasic patients. Neuropsychologia 1977; 15:351-4.

${ }^{26}$ Brooks DN. Recognition memory and head injury. $J$ Neurol Neurosurg Psychiatry 1974;37:794-801.

${ }^{27}$ Williams M. Errors in picture recognition after ECT. Neuropsychologia 1973;11:429-36.

${ }^{28}$ Warrington EK. Deficient recognition memory in amnesics. Cortex 1974;10:289-91.

${ }^{29}$ Cronholm B, Ottosson J-O. Memory functions in endogenous depression before and after ECT. Arch gen Psychiatry 1961;5:193-9.

${ }^{30}$ Fodor IE. Impairment of memory functions after acute head injury. J Neurol Neurosurg Psychiatry 1972;35:818-24.

${ }^{31}$ Piercy M. Experimental studies of the organic amnesic syndrome. In: Whitty CWM, Zangwill OL, eds. Amnesia (2nd edition). London: Butterworths, 1977.

${ }^{32}$ Miller E. Abnormal Ageing. London: John Wiley, 1977.

${ }^{33}$ Webster DD. Critical analysis of the disability in Parkinson's disease. Mod Treatment 1968;5:257-82.

${ }^{34}$ Parks TE. Signal-detectability theory of recognitionmemory performance. Psych Rev 1966;73:44-58.

${ }^{35}$ Freeman PR. Tables of $d^{\prime}$ and $\beta$. London: CUP, 1973.

${ }^{36}$ Asso D, Crown S, Russell JA, Logue V. Psychological aspects of the stereo-taxic treatment of Parkinsonism. Br J Psychiatry 1969;115:541-553.

${ }^{37}$ Perret E, Kohenof M, Siegfried J. Influences de lesions thalamiques unilaterales sur les fonctions intellectuelles amnesiques et d'apprentissage de malades Parkinsoniens. Neuropsychologia 1969;7:79-88.

${ }^{38}$ Lees AJ, Smith E. Cognitive deficits in the early stages of Parkinson's disease. Brain 1983;106:257-70. 